\title{
Determination of Trace Metallic Constituents in Nuclear-grade Be0 Matrix by D.C. Arc Carrier Distillation and ICP-AES: A Comparative Evaluation
}

\author{
S. Pathak ${ }^{\mathrm{a}}$, Sk. Jayabun ${ }^{\mathrm{a}}$, B. Rajeswaria , N. Pathak ${ }^{\mathrm{a}}$, M. Mohapatra ${ }^{\mathrm{a}, \mathrm{b}}$, Arijit Sengupta*,a, and R.M. Kadam ${ }^{\mathrm{a}, \mathrm{b}}$ \\ ${ }^{a}$ Radiochemistry Division, Bhabha Atomic Research Centre, Mumbai, India \\ ${ }^{b}$ Homi Bhabha National Institute, Mumbai, India
}

\section{INTRODUCTION}

Chemical quality control is an essential part for the characterization of nuclear materials and includes trace metal assay of base materials, intermediate and final products (1-3). Beryllium oxide (BeO) crystallizes in the hexagonal wurtzite structure and is used in rocket engines and as a transparent protective over-coating on aluminized telescope mirrors (4-6). The high thermal conductivity blended with an electrical insulator makes BeO useful in many highperformance semiconductor parts. BeO has extensively been used as structural ceramic for high-performance microwave devices, vacuum tubes, magnetrons, and gas lasers. $\mathrm{BeO}$ is also carcinogenic and can lead to chronic beryllium disease. However, the ceramic form is not a hazardous waste under U.S. federal law. In the nuclear reactor, $\mathrm{BeO}$ has been used as a neutron reflector (7-8). In view of such technological importance, stringent chemical quality control of $\mathrm{BeO}$ is essential to achieve its desired performance either in the nuclear, semiconductior, and thermo-electric industries.

In general, D.C. arc carrier distillation is routinely applied for trace characterization of nuclear materials (9-12). This is a solid state route involving the least handling of the samples, which is highly important in order to avoid process pickup and radio-toxicity of the nuclear materials. In the carrier distillation approach, suitable material is used

\footnotetext{
*Corresponding autbor.

E-mail: arijita@barc.gov.in

Tel: +912225590630
}

\section{ABSTRACT}

A comparative evaluation was carried out to determine the trace metallic constituents in nuclear-grade $\mathrm{BeO}$ by D.C. arc carrier distillation and inductively coupled plasma atomic emission spectrometry. D.C. arc carrier distillation is accomplished by physical separation of the major matrix to avoid interference, while ICP-AES employs the solution route because chemical separation of the major matrix is preferred. The method was optimized for $\mathrm{Ca}, \mathrm{Fe}, \mathrm{Mg}, \mathrm{Mn}, \mathrm{Si}, \mathrm{Na}$, $\mathrm{Li}, \mathrm{Al}, \mathrm{B}, \mathrm{Cd}, \mathrm{Cr}, \mathrm{Cu}, \mathrm{Ni}$, and $\mathrm{Zn}$ at minor and trace levels and was optimized using multiple standards and validated using synthetic samples. The analytical performance for both techniques, including detection limits, sensitivity, linear dynamic range, etc., was compared. Though both techniques were found to be suitable for analysis of nuclear-grade BeO samples, some differences were observed. ICP-AES provides better analytical performance, while D.C. arc requires less sample handling, minimizes process pickup, and results in less toxic expossure in the laboratory.

to physically separate the analytes from the refractory matrix on the basis of volatilization. This separation is a prerequisite for emissionrich nuclear materials to avoid matrix effects pertaining to spectral interference (13-16). Though this technique is advantageous in some cases, limitations do exist. The arc not being an optically thin source, self-absorption is one of the predominating factors in reducing the linear dynamic range of the analysis; hence, the sigmoid curve is expected. Each replicate measurement is associated with a different arc and indepedent arc characteristics. Arc wandering is another major issue resulting in the reduction of poor precision of the analysis. In the case of rare earth element analysis, d.c. arc suffers a major issue since the rare earth elements form refractory oxides. Therefore, not sufficient amount of these analytes can reach the arc and as a result, it is practically impossible to achieve very low detection limits using this arrangement.

On the other hand, ICP-AES offers simultaneous multi-element determination of the analytes with a wide range of concentrations (1720). ICP-AES is known for its analytical merits such as wide linear dynamic range, high sensitivity, very low detection limits, and high degree of precision. Since the radio frequency plasma is optically thi and a stable source, self-absorption and precision are higher in comparison to D.C. arc carrier distillation. The high temperature (6000 - 6500 $\mathrm{K}$ ) of the plasma in the analytical zone provides more energy for excitation and atomization of the analytes, resulting in more emission lines compared to D.C. arc carrier distillation. In ICP-AES, the atomic as well as the ionic lines can be observed. This provides the option for choosing multiple analytical lines for the determination of the analytes; however, it would also lead to spectral interference mainly from emission-rich elements. Preferential separation of these elements from the actual analytes/ samples is a prerequisite and is 
achieved by chemical separation and using solvent extraction or solid phase chromatographic separation.

In view of these differences of methods, a comparative evaluation was carried out for the chemical quality control of nuclear-grade $\mathrm{BeO}$ and its trace metallic impurities by D.C. arc carrier distillation and by ICP-AES.

\section{EXPERIMENTAL}

\section{Reagents and Standard Solutions}

The standard solutions for the individual elements were prepared from CertiPUR ${ }^{\circledR}$ ICP standard reference material solutions (E-Merck, Germany). Suprapur ${ }^{\circledR} \mathrm{HNO}_{3}$ (EMerck, Germany) and quartz double-distilled water were used throughout this study. Multi-point standardization was carried out for ICP-AES analysis. The optimized ICP-AES conditions are listed in Table I

\section{ICP-AES Instrumental Operating} Conditions for $\mathrm{BeO}$ Sample Analysis

An atomic emission spectrometer (SpectroArcos, Germany) with ICP source and coupled with a D.C. arc system with a charge coupled device (CCD) as the detector was used for the impurity analyses (21). Unlike a photomultiplier tube, different pixels present in the CCD detector give a 2D image of the spectra. The cartridge associated with the detection can provide the detection in a vacuum or in an Ar atmosphere to avoid interference from the environment. Ar flushing is a prerequisite to open the slit for any detection, resulting in reduction of background as well as keeping the detector safe. The detector system, consisting of linear arrays of CCD detectors (3648 pixels/ array), thermally stabilized, provides the ability to choose the alternate analytical lines. High purity argon plasma was used for the excitation source. To establish the calibration curves for the analytes, the solution standards in the concentration range of 1-100 ppm were prepared from Specpure solutions. Since ICP-AES has a large dynamic range, linear correlations between concentrations and intensity were obtained to establish the calibration curves. Triplicate measurements were carried out to report each data. The dilution was done using $1 \mathrm{M} \mathrm{HNO}_{3}$ and the same solution was also used as a blank.

\section{Sample Preparation for ICP-AES Analysis}

For the ICP-AES analysis of actual BeO samples, the solid powder was allowed to dissolve in concentrated $\mathrm{HNO}_{3}$ under an infrared lamp. After repeated evaporation to dryness, the medium was kept $1 \mathrm{M} \mathrm{HNO}_{3}$. This will lead to complete dissolution of the matrix along with the metallic impurities mainly in nitrate form.

D.C. Arc Carrier Distillation Technique for BeO Sample Analysis

For d.c. arc carrier distillation, the same detector system was used. However, the sample introduction and the power supply differed. The
ASTM designation E-130-66 type S-2 on a S-1 pedestal was used as the anode, while pointed electrode of ASTM designation E-130-66 type C-1 was used as the cathode. Since $\mathrm{BeO}$ has a lower density, a $40 \mathrm{mg}$ charge was used for the carrier distillation technique. AgCl of 10\% composition was used as the carrier to physically separate the analytes from the matrix elements. The sample charge was put on anode after complete homogenization of the samples with the carrier having almost similar particle size. Subsequently, the charge was tapped for proper packing of the samples inside the anode, while venting was done to keep the passage of any gas, if generated, during arcing. This also helped to avoid any sample charge going directly to the arc. After the arc is generated by the appropriate current and arc gap (as specified in Table II), the electrons from the pointed cathode collimated towards the sample charge on the anode. This impact can lead to excitation of the analytes into the arc. The arc temperature achieved is $\sim 2500 \mathrm{~K}$ and is sufficient only for excitation of the atomic lines of the analytes. The analytes in the d.c. arc can be divided into different groups depending on the volatility

TABLE I

Optimized Instrumental Parameters for ICP-AES

\begin{tabular}{ll}
\hline Optical design & $750 \mathrm{~mm}$ and P-R mounting \\
Grating & Holographic, ion-etched optical grating \\
Groove density & 1800 and 3600 grooves $/ \mathrm{mm}$ \\
Grating size & $110 \times 110 \mathrm{~mm}$ \\
Wavelength range & $120-800 \mathrm{~nm}$ \\
Bandpass & $0.0023 \mathrm{~nm}$ from 120 to $340 \mathrm{~nm}$ \\
& $0.0046 \mathrm{~nm}$ from 340 to $800 \mathrm{~nm}$ \\
Thermal regulation & Controlled to $30 \pm 1^{\circ} \mathrm{C}$ \\
Frequency & $27.12 \mathrm{MHz}$ \\
Pump & Dual channel $(12$ roller $)$ \\
Nebulizer & Pneumatic concentric \\
Ar plasma flow & $12 \mathrm{~L} / \mathrm{min}$ \\
Integration time & $11 \mathrm{~s}$ \\
Sample rate & $1 \mathrm{~mL} / \mathrm{min}$ \\
\hline
\end{tabular}


characteristics. It should be noted that the intensity response with respect to the concentration is sigmoid in nature, not linear. Therefore, the calibration curve must be in logarithmic scale to establish the linear dynamic range. Table II summarizes the arc characteristics.

For D.C. arc standard preparation, a master impurity mixture was pepared by grinding the metallic elements, mostly in their oxide form. An intermediate range concentration standard was prepared synthetically by homogeneous mixing of a certain portion of the master impurity mixture, base material (Specpure $\mathrm{BeO}$ ), and 10\% $\mathrm{AgCl}$ as the carrier. These two standards were arced for finalizing the preburn and exposure time for each analyte and using the experimental procedure adopted earlier for other matrices. A series of five analytical standards were prepared by grinding a mixture of graded portions of the master impurity mixture, $10 \%$ $\mathrm{AgCl}$, and the balance amount of base material. A blank standard was also prepared in a similar manner but without any master impurity mixture. Repetitive analyses of all standards using optimized experimental parameters were carried out, and the data obtained were used to get the best fit for the calibration curve for each analytical channel. The data were stored in the computer in the form of a slope, intercept, curvature, and exponent of each analytical curve

\section{TABLE II}

D.C. Arc-AES Experimental Parameters for Determination of the Analytes

Standard/sample charge on electrode $40 \mathrm{mg}$

Carrier $10 \% \mathrm{AgCl}$

D.C. arc current

Arc gap $4 \mathrm{~mm}$

Pre-burn time $10 \mathrm{sec}$ Exposure time $30 \mathrm{sec}$ for subsequent use in the two-point standardization procedure for the analysis of the samples. The intermediate concentration standard was arced repeatedly using optimized parameters to obtain the precision data. Table III summarizes the concentrations of different analytes in the prepared standards.

For optimization of the methodologies, synthetic solid standards were used in D.C. arc carrier distillation and the same standards were used for ICP-AES analysis after dissolution. The detection limits for the analytes in the BeO matrix were calculated based on the expression $<\mathrm{x}\rangle+3 \sigma$, where, $\langle\mathrm{x}\rangle$ is the average of the blank values for replicate measurements, and $\sigma$ is the standard deviation of that measurement. The slope of the calibration curves were used as the sensitivity, which physically meant the response corresponds to the unit concentration.

\section{RESULTS AND DISCUSSION}

Especially in the nuclear industries, each BeO batch has to pass through stringent quality control before being put into the reactor. This is essential not only to achieve the desired performance, but also for safe nuclear operations. Different metallic impurities were found to have detrimental effects in the thermo-physical, mechanical, and chemical properties of $\mathrm{BeO}$. To cite a few examples, certain trace metals with a high neutron absorption cross-section, such as $\mathrm{B}, \mathrm{Cd}$, and the rare earth elements $\mathrm{Eu}, \mathrm{Sm}, \mathrm{Gd}$, and Dy, have to be well below their

\section{Atomic Apectroscopy 1 Vol. 40(6), Nov./Dec. 2019}

maximum permissible concentrations, since the neutron economy is of utmost importance to sustain the nuclear reaction in the reactor in a controllable manner. Refractory elements, i.e., W, Mo, etc., can result in creep resistance (22), while low melting elements, such as $\mathrm{Zn}$, can lead to liquid-metal embrittlement. The presence of common metallic analytes ( $\mathrm{Fe}, \mathrm{Cr}$, $\mathrm{Ni}$, etc.) cannot only indicate the possibility of process pickup but also can lead to problems during sintering. Thus, the fuel designer has prescribed the limits of tolerance of these analytes for BeO samples, also known as specification limits. As seen from Table IV, the specification limits for $\mathrm{B}, \mathrm{Cd}$, and $\mathrm{Li}$ were found to be very low. The elements $\mathrm{Mn}, \mathrm{Cr}$, and $\mathrm{Cu}$ were found to have specification limits below $100 \mathrm{ppm}$, whereas for $\mathrm{Ca}, \mathrm{Fe}, \mathrm{Mg}$, $\mathrm{Si}, \mathrm{Na}, \mathrm{Ni}$, and $\mathrm{Zn}$ the specification limits are below $650 \mathrm{ppm}$. In case of Al, more than 1000 ppm was allowed in the $\mathrm{BeO}$ matrix.

The analytical performance of the analytes in d.c. arc carrier distillation and ICP-AES are shown in Table V. The detection limits for ICP-AES were found to be almost an order of magnitude better compared to the D.C. arc carrier distillation technique, which can be attributed to the higher temperature in the analytical zone of the ICP-AES leading to more excitation and emission. The sensitivity for the d.c. arc was also found to be poorer than that of ICP-AES, mainly attributed to the same reason. The linear dynamic range for d.c. arc is also poorer due to the self-absorp-

TABLE III

Concentration of the Analytes in the Standards

\begin{tabular}{lccccc}
\hline Elements & Std. 1 & Std. 2 & $\begin{array}{r}\text { Std. 3 } \\
(\mathrm{ppm})\end{array}$ & Std. 4 & Std. 5 \\
\hline $\mathrm{B}, \mathrm{Cd}, \mathrm{Li}$ & 0.1 & 0.4 & 1 & 4 & 10 \\
$\begin{array}{l}\mathrm{Ca}, \mathrm{Fe}, \mathrm{Mg}, \mathrm{Mn}, \mathrm{Si}, \mathrm{Na}, \\
\mathrm{Al}, \mathrm{Cr}, \mathrm{Cu}, \mathrm{Ni}, \mathrm{Zn}\end{array}$ & 5 & 20 & 50 & 200 & 500 \\
\hline
\end{tabular}


TABLE IV

Specification Limits for the Analytes in $\mathrm{BeO}$ Matrix

\begin{tabular}{lc}
\hline Element & $\begin{array}{c}\text { Specification Limit } \\
(\text { ppm })\end{array}$ \\
\hline $\mathrm{Ca}$ & 500 \\
$\mathrm{Fe}$ & 600 \\
$\mathrm{Mg}$ & 600 \\
$\mathrm{Mn}$ & 36 \\
$\mathrm{Si}$ & 600 \\
$\mathrm{Na}$ & 360 \\
$\mathrm{Li}$ & 7 \\
$\mathrm{Al}$ & 1100 \\
$\mathrm{~B}$ & 1 \\
$\mathrm{Cd}$ & 1.5 \\
$\mathrm{Cr}$ & 90 \\
$\mathrm{Cu}$ & 36 \\
$\mathrm{Ni}$ & 360
\end{tabular}

tion caused by the optically nonthin source.

Table VI shows the analytical results for two synthetic samples, one in the lower concentration range and the other in higher concentration range. Both the D.C. arc and the ICP-AES techniques were found to be successful in analyzing the synthetic samples. However, the ICP-AES results were more precise in comparison to the d.c. arc carrier distilation technique. All of the values listed are the average of five replicate measurements and the values were reported based on the $99 \%$ confidence interval, i.e., $\sim 3 \sigma$, where $\sigma$ is the relative standard deviation associated with the measurement. It should also be noted that the precision values calculated from the analyses were found to be $~ 20 \%$ for D.C. arc, while 5\% for ICP-AES. Source stability and arc wandering are responssible factors for this difference (as discussed earlier).

Table VII summarizes the compartive characterization of the
TABLE V

Comparative Evaluation of Analytical Performance of D.C. Arc Carrier Distillation and the ICP-AES for BeO Samples

\begin{tabular}{|c|c|c|c|c|c|c|c|}
\hline & \multicolumn{4}{|c|}{ D.C. Arc Carrier Distillation } & \multicolumn{3}{|c|}{ ICP-AES } \\
\hline $\begin{array}{l}\text { Ele- } \\
\text { ment }\end{array}$ & $\begin{array}{l}\text { Anal. } \\
\text { Line } \\
(\mathrm{nm})\end{array}$ & $\begin{array}{r}\text { D.L. } \\
\text { (ppm) }\end{array}$ & $\begin{array}{l}\text { Sensitivity } \\
\text { (counts/ } \\
\text { ppm) }\end{array}$ & $\begin{array}{c}\text { Linear } \\
\text { Dynamic } \\
\text { Range } \\
(\mathrm{ppm})\end{array}$ & $\begin{array}{c}\text { D.L. } \\
\text { (ppm) }\end{array}$ & $\begin{array}{l}\text { Sensitivity } \\
\text { (counts/ } \\
\text { ppm) }\end{array}$ & $\begin{array}{c}\text { Linear } \\
\text { Dynamic } \\
\text { Range } \\
(\mathrm{ppm})\end{array}$ \\
\hline $\mathrm{Ca}$ & 396.8 & 2 & 7.6 & $10-400$ & 0.1 & 41 & $0.1-500$ \\
\hline $\mathrm{Fe}$ & 261.7 & 4 & 8.3 & $5-450$ & 0.08 & 32 & $0.08-500$ \\
\hline $\mathrm{Mg}$ & 280.2 & 3 & 11 & $7-350$ & 0.06 & 45 & $0.06-500$ \\
\hline Mn & 257.6 & 4 & 14 & $5-500$ & 0.05 & 29 & $0.05-500$ \\
\hline Si & 288.1 & 5 & 2.9 & $10-400$ & 0.5 & 24 & $0.5-500$ \\
\hline $\mathrm{Na}$ & 588.9 & 5 & 4.1 & $5-450$ & 0.08 & 39 & $0.08-500$ \\
\hline $\mathrm{Li}$ & 670.7 & 0.2 & 11 & $0.2-8$ & 0.05 & 31 & $0.05-500$ \\
\hline Al & 308.2 & 5 & 14 & $10-400$ & 0.08 & 49 & $0.08-500$ \\
\hline B & 249.7 & 0.1 & 12 & $0.15-10$ & 0.04 & 40 & $0.04-500$ \\
\hline $\mathrm{Cd}$ & 228.8 & 0.1 & 9 & $0.1-10$ & 0.04 & 38 & $0.04-500$ \\
\hline $\mathrm{Cr}$ & 357.8 & 6 & 8.7 & $10-350$ & 0.1 & 28 & $0.1-500$ \\
\hline $\mathrm{Cu}$ & 324.7 & 5 & 10 & $10-500$ & 0.2 & 29 & $0.2-500$ \\
\hline $\mathrm{Ni}$ & 231.6 & 4 & 9.1 & $10-450$ & 0.09 & 27 & $0.09-500$ \\
\hline $\mathrm{Zn}$ & 213.8 & 6 & 7.7 & $10-400$ & 0.08 & 30 & $0.08-500$ \\
\hline
\end{tabular}

Table VI

Comparison of Analytical Results for Synthetic Samples by D.C. Arc and ICP-AES (in ppm)

\begin{tabular}{c|ccc|ccc}
\hline $\begin{array}{c}\text { Ele- } \\
\text { ment }\end{array}$ & Actual & $\begin{array}{c}\text { D.C. Arc } \\
\text { Estimated }\end{array}$ & $\begin{array}{c}\text { ICP-AES } \\
\text { Estimated }\end{array}$ & Actual & $\begin{array}{c}\text { D.C. Arc } \\
\text { Estimated }\end{array}$ & $\begin{array}{c}\text { ICP-AES } \\
\text { Estimated }\end{array}$ \\
\hline $\mathrm{Ca}$ & 20 & $18 \pm 4$ & $19.5 \pm 0.5$ & 200 & $220 \pm 31$ & $195 \pm 9$ \\
$\mathrm{Fe}$ & 20 & $19 \pm 3$ & $20.1 \pm 0.4$ & 200 & $213 \pm 24$ & $207 \pm 8$ \\
$\mathrm{Mg}$ & 20 & $22 \pm 4$ & $18.7 \pm 0.7$ & 200 & $170 \pm 41$ & $192 \pm 8$ \\
$\mathrm{Mn}$ & 20 & $20 \pm 4$ & $19.0 \pm 0.5$ & 200 & $250 \pm 40$ & $195 \pm 9$ \\
$\mathrm{Si}$ & 20 & $19 \pm 3$ & $20.3 \pm 0.5$ & 200 & $162 \pm 32$ & $201 \pm 10$ \\
$\mathrm{Na}$ & 20 & $17 \pm 4$ & $19.7 \pm 0.8$ & 200 & $178 \pm 29$ & $206 \pm 9$ \\
$\mathrm{Li}$ & 0.4 & $0.29 \pm 0.05$ & $0.37 \pm 0.02$ & 4 & $4.2 \pm 0.4$ & $3.9 \pm 0.2$ \\
$\mathrm{Al}$ & 20 & $16 \pm 4$ & $19.4 \pm 0.7$ & 200 & $233 \pm 38$ & $190 \pm 9$ \\
$\mathrm{~B}$ & 0.4 & $0.50 \pm 0.09$ & $0.41 \pm 0.02$ & 4 & $3.4 \pm 0.5$ & $4.3 \pm .2$ \\
$\mathrm{Cd}$ & 0.4 & $0.47 \pm 0.09$ & $0.38 \pm 0.01$ & 4 & $3.8 \pm 0.6$ & $4.0 \pm 0.1$ \\
$\mathrm{Cr}$ & 20 & $18 \pm 4$ & $21.0 \pm 0.9$ & 200 & $177 \pm 27$ & $204 \pm 6$ \\
$\mathrm{Cu}$ & 20 & $22 \pm 4$ & $19.1 \pm 0.5$ & 200 & $190 \pm 30$ & $197 \pm 8$ \\
$\mathrm{Ni}$ & 20 & $23 \pm 4$ & $19.6 \pm 0.5$ & 200 & $220 \pm 25$ & $192 \pm 8$ \\
$\mathrm{Zn}$ & 20 & $18 \pm 3$ & $20.4 \pm 0.6$ & 200 & $197 \pm 20$ & $204 \pm 7$ \\
\hline
\end{tabular}




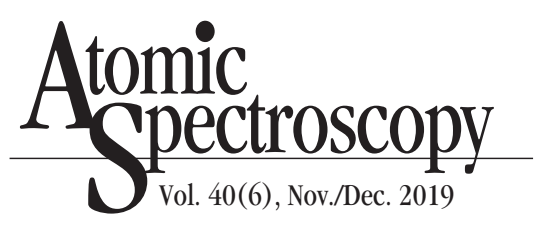

actual $\mathrm{BeO}$ samples by d.c.arc and ICP-AES. In the first two samples, $\mathrm{B}$ and $\mathrm{Cd}$ were found to be less than $0.3 \mathrm{ppm}$, while for the $3 \mathrm{rd}$ sample, these two elements are less than $1 \mathrm{ppm}$. The Li values for these samples are less than $6 \mathrm{ppm}$. These three elements are described separately, since their specification limits are very low. S1 and S2 were found to be of similar purity. $\mathrm{Mg}$, $\mathrm{Mn}, \mathrm{Al}, \mathrm{Cr}, \mathrm{Ni}$, and $\mathrm{Zn}$ were present in the range $10-15 \mathrm{ppm}$, while $\mathrm{Si}$, $\mathrm{Fe}$, and $\mathrm{Ca}$ were present in the range 20-30 ppm. However, S3 was found to have more metallic impurities. $\mathrm{Si}, \mathrm{Na}$, and $\mathrm{Al}$ were found to be in the range of $150-250 \mathrm{ppm}$. These three samples were found to have impurities lower than the specification limits of the individual elements as seen from both the D.C. arc and ICP-AES techniques. Apart from the precision, the analytical results from both methods were in good agreement.

\section{CONCLUSION}

A comparative evaluation was carried out for the determination of $\mathrm{Ca}, \mathrm{Fe}, \mathrm{Mg}, \mathrm{Mn}, \mathrm{Si}, \mathrm{Na}, \mathrm{Li}, \mathrm{Al}, \mathrm{B}, \mathrm{Cd}$, $\mathrm{Cr}, \mathrm{Cu}, \mathrm{Ni}$, and $\mathrm{Zn}$ at minor and trace level in a nuclrear-grade $\mathrm{BeO}$ matrix by D.C. arc carrier distillation and ICP-AES. The former method used solid samples and 10\% $\mathrm{AgCl}$ as the carrier gas to sweep away the analytes into the arc, while the latter method requires dissolution of the samples. The d.c. arc is associated with less sample handling, resulting in less process pickup and less chemical as well as radio-toxic expossure to indiviuals. However, the linear dynamic range of the d.c.arc is less wide compared to ICP-AES due to the self-absorption phenomena pertianing to the non-optical thin source. The arc wandering and stability of the plasma were found to be responssible for poorer precision in the d.c.arc carrier distillation technique. The analytical results

TABLE VII

Analyses of Real BeO Samples by D.C. Arc and ICP-AES (in ppm)

\begin{tabular}{c|cc|cc|cc}
\hline Ele- & \multicolumn{2}{|c|}{ S1 } & \multicolumn{2}{c|}{ S2 } & \multicolumn{2}{c}{ S3 } \\
ment & D.C. Arc & ICP & D.C. Arc & ICP & D.C. Arc & ICP \\
\hline $\mathrm{Ca}$ & $25 \pm 4$ & $26 \pm 1$ & $22 \pm 3$ & $20 \pm 1$ & $60 \pm 9$ & $53 \pm 2$ \\
$\mathrm{Fe}$ & $32 \pm 5$ & $30 \pm 1$ & $28 \pm 5$ & $23 \pm 1$ & $81 \pm 9$ & $88 \pm 3$ \\
$\mathrm{Mg}$ & $12 \pm 2$ & $11.6 \pm 0.3$ & $15 \pm 3$ & $16 \pm 1$ & $47 \pm 9$ & $40 \pm 2$ \\
$\mathrm{Mn}$ & $10 \pm 2$ & $10.4 \pm 0.3$ & $10 \pm 3$ & $8.4 \pm 0.3$ & $25 \pm 5$ & $30 \pm 1$ \\
$\mathrm{Si}$ & $30 \pm 5$ & $25 \pm 1$ & $28 \pm 4$ & $30 \pm 1$ & $154 \pm 20$ & $140 \pm 8$ \\
$\mathrm{Na}$ & $5.0 \pm 0.9$ & $6.1 \pm 0.2$ & $4.2 \pm 0.7$ & $3.5 \pm 0.1$ & $200 \pm 31$ & $210 \pm 8$ \\
$\mathrm{Li}$ & $4.2 \pm 0.7$ & $5.0 \pm 0.2$ & $5.1 \pm 0.8$ & $4.5 \pm 0.2$ & $6 \pm 1$ & $5.3 \pm 0.3$ \\
$\mathrm{Al}$ & $10 \pm 2$ & $9.8 \pm 0.3$ & $14 \pm 3$ & $13 \pm 1$ & $240 \pm 30$ & $210 \pm 10$ \\
$\mathrm{~B}$ & $0.15 \pm 0.02$ & $0.11 \pm 0.01$ & $0.25 \pm 0.05$ & $0.22 \pm 0.01$ & $0.80 \pm 0.06$ & $0.71 \pm 0.02$ \\
$\mathrm{Cd}$ & $0.10 \pm 0.02$ & $0.15 \pm 0.01$ & $0.2 \pm 0.04$ & $0.21 \pm 0.01$ & $0.91 \pm 0.04$ & $0.87 \pm 0.03$ \\
$\mathrm{Cr}$ & $10 \pm 2$ & $9.8 \pm 0.5$ & $12 \pm 3$ & $10 \pm 1$ & $73 \pm 9$ & $80 \pm 3$ \\
$\mathrm{Cu}$ & $5.1 \pm 0.8$ & $6.0 \pm 0.2$ & $5.9 \pm 0.7$ & $6.4 \pm 0.2$ & $9.0 \pm 1.6$ & $8.5 \pm 0.3$ \\
$\mathrm{Ni}$ & $12 \pm 3$ & $11 \pm 1$ & $10 \pm 2$ & $11 \pm 1$ & $38 \pm 6$ & $33 \pm 3$ \\
$\mathrm{Zn}$ & $10 \pm 2$ & $8.9 \pm 0.3$ & $15 \pm 3$ & $13 \pm 1$ & $28 \pm 4$ & $30 \pm 1$ \\
\hline
\end{tabular}

obtained from both methods were found to be in good agreement.

\section{ACKNOWLEDGMENT}

The authors wish to acknowledge the constant support of Dr. P.K. Pujari, Head, and AD RC \& IG, Bhabha Atomic Research Centre, Mumbai, India.

\section{Received July 25, 2019.}

\section{REFERENCES}

1. A. Sengupta, B. Rajeswari, R. M. Kadam, and S. V. Godbole, At. Spectrosc. 33(2), 48 (2012).

2. P.S. Somayajulu, A. Sengupta, A.K. Karande, R. Malav, D.K. Das and Mohd. Afzal, J. Radioanal. Nucl. Chem. 308(2), 495 (2016).

3. N. Pathak,V.C. Adya, S.K. Thulasidas, A. Sengupta, T.K. Seshagiri, and S.V. Godbole, At. Spectrosc. 35(1), 17 (2014).

4. G. A. Day, A. B. Stefaniak, A. Weston and S. S. Tinkle, Int. Archives Occupational Environ. Health 79(2), 161 (2006).

5. T. M. Sabine, A. W. Pryor and B. S.
Hickman, Nature 191, 1385 (1961).

6. O. F. Schirmer, K. A. Müller and J. Schneider, Physik der kondensierten Materie 3(4), 323 (1965).

7. I.V. Dulera and R.K. Sinha, J. Nucl Matr. 383(1-2), 183 (2008).

8. W.D. Manly, J. Nucl. Matr. 14, 3 (1964).

9. A. Sengupta, V.C. Adya, T.K. Seshagiri, S.K. Thulasidas, S.V. Godbole, and V. Natarajan, J. Res. Spectrosc. DOI: $10.5171 / 2014.757111,2014$, 757111(2014)

10. B. F. Scribner and H. R. Mullin, J. Res. Nat. Bureau Standards 37, RPI 753 (1946).

11. T. R. Bangia , V. C. Adya , B. A. Dhawale , B. Rajeswari , M. D. Sastry and P.R. Natarajan, Anal. Lett. 23(1), 147 (1990).

12. N. K. Porwal, A. A. Argekar, P. J. Purohit, A. G. Page and M. D. Sastry, Fresenius' J. Anal. Chem. 338(3), 255 (1990).

13. A. Sengupta, N. K. Gupta and Y. Airan, At. Spectrosc. 38(2), 48 (2017).

14. A. Sengupta, Y. Airan, S.K. Thulasidas and V. Natarajan, At. Spectrosc. 37(2), 50(2016). 
15. P.W.J.M. Boumans, Anal. Chem. 66(8), 459 (1994).

16. E.H. van Veen, F..J. Oukes and M.T.C. de Loos-Vollebregt, Spectrochim. Acta 45 (10), 1109 (1990).

17. K. Satyanarayana and S. Durani, J. Radioanal. Nucl. Chem.285(3), 659-665 (2010).

18. A. Sengupta, S. K. Thulasidas and V. Natarajan, J. Radioanal. Nucl. Chem. 303, 2421 (2015).

19. A. Sengupta, M. J. Kulkarni, S.V. Godbole, V.Natarajan and P.N. Pathak, At. Spectrosc. 35(2), 60(2014).

20. J. L. Todolí, L. Gras , V. Hernandis and J. Mora, J. Anal. At. Spectrom. 17, 142 (2002).

21. V.C. Adya, A. Sengupta and S.V. Godbole, At. Spectrosc. 35(1), 25(2014).

22. V. Venugopal, Ind. Assoc. Nucl. Chem. Allied Sci. Bull. 4, 205 (2005. 